Article

\title{
Evaluating Personal Default Risk in P2P Lending Platform: Based on Dual Hesitant Pythagorean Fuzzy TODIM Approach
}

\author{
Xiaonan Ji, Lixia Yu* and Jiapei Fu \\ Business School, Sichuan Normal University, Chengdu 610101, Sichuan, China; \\ 20181901002@stu.sicnu.edu.cn (X.J.); 20181901005@stu.sicnu.edu.cn (J.F.) \\ * Correspondence: yulixia@sicnu.edu.cn
}

Received: 26 November 2019; Accepted: 11 December 2019; Published: 18 December 2019

\begin{abstract}
An extended approach proposed in this paper is to make a more reasonable assessment of personal default risk in peer to peer (P2P) online lending platform, which reduces uncertainty while taking into account the psychological characteristics of lenders to avoid risk. The TODIM (an acronym in Portuguese of interactive and multi-criteria decision making) approach, which can describe the psychological behaviors of decision maker, has been proved to be effective to solve multi-attribute decision making (MADM) problems. The definitions of dual hesitant Pythagorean fuzzy set (DHPFS) and the processes of traditional TODIM approach are firstly introduced in this paper. Then, the TODIM approach is extended to solve the MADM problems with a dual hesitant Pythagorean fuzzy number (DHPFN). Finally, a case study evaluating the personal default risk in P2P online lending is conducted to demonstrate that the proposed approach is applicable to solve MADM problems. In addition, some comparative analyses are performed to compare the dual hesitant Pythagorean fuzzy TODIM method with the other two integrated operators of DHPFS. Through the comparisons, we conclude that the advantage of the proposed method over other methods is that it reduces uncertainty while taking into account the psychological characteristics of lenders to avoid risk. Today's credit environment is fraught with risks, and the psychological behaviors of decision makers are important factors that cannot be ignored. For these reasons, the dual Pythagorean hesitant fuzzy TODIM method is applicable for evaluating personal default risk.
\end{abstract}

Keywords: dual hesitant Pythagorean fuzzy set; multi-attribute decision making; TODIM approach; psychological behaviors; peer to peer; evaluating personal credit

\section{Introduction}

P2P network lending is a new type of lending model. As a website that provides intermediary services, it connects capital applicants and providers together. Due to its relatively high rate of return while low threshold, requirement and cost, P2P online lending provides an important channel for borrowers who have difficulty in obtaining financing from the traditional financial industry. This lending model has been popularized nationwide. In 2007, the first P2P platform in China was established in Shanghai, then there was a blowout in 2015. In fact, there was little interference in P2P by regulators before 2018. But with the continuous upgrading of financial regulation after that, P2P continued to suffer from explosion, suspension, losing contact, withdrawal difficulties, platform fraud and other problems, and those phenomena disrupted the normal financial order. By November 2019, the total loan balance of normal operating platforms of P2P was 540.828 billion yuan, and the transaction volume was 50.623 billion yuan. Compared with the November of last year, the total loan balance declined by 33.33 percent, and the transaction volume dropped by 54.58 percent. Recently, 
some provinces, such as Hunan, Shandong, Chongqing, and Sichuan have announced a crackdown on non-compliant P2P business. At present, the biggest risk of P2P lending is default risk, which has become the main bottleneck of the development of P2P industry. How to evaluate the borrower's default risk is particularly important for the normal operation of P2P. Therefore, this article attempts to propose a new method to evaluate the borrower's default risk in P2P online lending.

In recent years, a lot of researchers studied on the personal default risk in the P2P online lending. Malekipirbazari [1] established a credit risk assessment model based on random forest classification method. Serrano-cinca [2] exceeded the traditional credit model, established the profit scoring model, and proved that the profit scoring model based on multiple regression was superior to the credit scoring system based on the logistic model. Oreski S. [3] proposed a personal credit assessment method combining genetic algorithm and neural network. Guo et al. [4] verified that the instance-based credit risk assessment model was superior to the score-based model.

Wei and Lu [5] proposed the dual hesitant Pythagorean fuzzy set (DHPFS), the definitions and basic algorithms of DHPFS were given in their paper. In DHPFS, both membership and non-membership are represented by sets. It is clear that DHPFS can get more valuable decision information from decision makers. Pythagorean fuzzy sets and dual hesitant fuzzy sets have their own outstanding advantages and application prospects. The combination of the two will make great contribution to the extension of fuzzy sets and make a difference in decision-making process [6].

MADM is an important part of decision science and expected utility theory is the theoretical basis of traditional MADM research. Expected utility theory believes that complete rationality is the characteristic of decision makers, and those persons' goal is to maximize benefits. In real life, the practical option of decision makers and best option based on rational decision theory have a certain deviation, owing to cognitive ability, emotion, psychology and other factors [7]. At present, some scholars have studied the MADM method which takes the psychological behavior of decision makers into account. Knhneman and Tversky put forward prospect theory [8], which is regarded to be the most influential theory in the field of behavioral decision making and has been widely used in MADM problems [9]. The theory mainly draws the following conclusions. First, most people have a risk-averse attitude to gains and a risk-appetite attitude to losses. Second, people are more sensitive to loss than gain. The pain of loss greatly exceeds the pleasure of gain, which is called "loss aversion". Third, most people tend to rely on reference points for their judgment of gains and losses, which is called "reference dependence". Gomes and Lima [10] proposed a TODIM decision making method based on prospect theory, which is a typical multi-attribute decision making method that takes the psychological behavior of decision makers into account. The TODIM method's main concepts are as follows. First, calculating the advantages of alternatives over other alternatives in various attributes based on the decision maker's reference dependence and the psychological behavior characteristics of loss avoidance. Then, the overall advantage of each scheme over other schemes is calculated, and finally, the objective function which can maximize the overall advantage and the optimal model is established respectively. The TODIM method has been deeply studied and applied to various decision-making problems by many scholars, such as choosing the best destination for natural gas storage [11] and evaluating green supply chain [12]. In order to describe both the uncertainty of MADM problems and the attitude of lenders to avoid risks, some scholars have successively proposed fuzzy TODIM method [13], intuitionistic fuzzy TODIM [14], Pythagoras fuzzy TODIM [15] and hesitant fuzzy TODIM [16]. Wei [17] proposed picture fuzzy TODIM method for MADM problems. Huang and Wei [18] proposed the Pythagoras binary semantic TODIM method. Ji et al. [19] applied the project-based multi-valued neutrophil set TODIM method to personnel selection. Tian et al. [20] proposed an extended TODIM based on cumulative prospect theory, and then applied it in venture capital. Yin et al. [21] proposed an extended TODIM to evaluate the competency of project manager, which combines lambda-fuzzy measure with Choquet integral. However, the dual hesitant Pythagoras fuzzy TODIM method has not been studied. 
Although there are a large number of methods for evaluating personal default risk, they do not take people's attitude to risk into account. At the same time, the decision environment contains too much uncertain information. So, risk and uncertainty are two important factors that should be taken into consideration when evaluating personal credit default risk. Previous research has found that TODIM is an effective method that can reflect people's attitude to risk, and dual hesitant Pythagoras fuzzy set can get more information from decision maker. Therefore, we are trying to apply TODIM method with dual hesitant Pythagoras fuzzy number to the personal default risk evaluation in P2P online lending. Our goal is to demonstrate the applicability of this approach in individual default risk evaluation and, more broadly, to apply it to more similar MADM problems.

In the next section, we will introduce the process of traditional TODIM approach, the concepts of Pythagorean fuzzy set, dual hesitant fuzzy set and dual hesitant Pythagorean fuzzy set. In Section 3, we shall propose the dual hesitant Pythagorean TODIM approach. In Section 4, a numerical example for evaluating personal credit risk in the P2P online lending platform with dual hesitant Pythagorean fuzzy information is used to demonstrate the approach's applicability. In Section 5, we will draw the conclusions about this paper.

\section{Preliminaries}

In this part, the process of traditional TODIM approach in decision making will be introduced briefly. Then, we retrospect the concepts and theories of dual hesitant Pythagorean fuzzy set (DHPFS).

\subsection{The TODIM Approach}

Let $A=\left\{A_{1}, A_{2}, \ldots, A_{m}\right\}$ be a discrete set with $m$ alternatives, and $A_{i}$ represents the ith alternative in the set. Let $C=\left\{C_{1}, C_{2}, \ldots, C_{n}\right\}$ be a set with $n$ attributes, and $C_{j}$ represents the $j$ th attribute in the set. Let $\omega=\left\{\omega_{1}, \omega_{2}, \ldots, \omega_{n}\right\}^{T}$ be the attributes set's weight vector, with $\omega_{j} \in[0,1]$ and $\sum_{j=1}^{n} \omega_{j}=1$. Suppose that $X=\left(x_{i j}\right)_{m \times n}$ be a decision matrix, where $x_{i j}$ is the attribute value according to a decision maker over the alternative $A_{i}$ with respect to attribute $C_{j}$. We define $\omega_{j r}=\omega_{j} / \omega_{r}(j, r=1,2, \ldots, n)$ as the relative weight of the attribute $C_{j}$ to $C_{r}, \omega_{r}=\max \left\{\omega_{j} \mid j=1,2, \ldots, n\right\}$, and $\omega_{j r} \in[0,1]$. Then, the steps of the traditional TODIM approach are as follows:

Step 1. Standardize the decision matrix $X=\left(x_{i j}\right)_{m \times n}$ into the matrix $Y=\left(y_{i j}\right)_{m \times n}$.

Step 2. Compute the dominance degree of $A i$ over each alternative $A k$ for attribute $C_{j}$ :

$$
\delta\left(A_{i}, A_{k}\right)=\sum_{j=1}^{n} \phi_{j}\left(A_{i}, A_{k}\right),(i, k=1,2, \ldots, m)
$$

where

$$
\phi_{j}\left(A_{i}, A_{k}\right)= \begin{cases}\sqrt{\left(y_{i j}-y_{k j}\right) \omega_{j r} /\left(\sum_{j=1}^{n} \omega_{j r}\right)}, & y_{i j}>y_{k j} \\ 0, & y_{i j}=y_{k j} \\ -\frac{1}{\theta} \sqrt{\left(y_{k j}-y_{i j}\right)\left(\sum_{j=1}^{n} \omega_{j r}\right) / \omega_{j r}}, & y_{i j}<y_{k j}\end{cases}
$$

and the attenuation factor of the losses is expressed by the parameter value $\theta$.

Step 3. Compute the overall value of the alternative $A_{i}$ by:

$$
\xi\left(A_{i}\right)=\frac{\sum_{k=1}^{m} \delta\left(A_{i}, A_{k}\right)-\min _{i \in M}\left\{\sum_{k=1}^{m} \delta\left(A_{i}, A_{k}\right)\right\}}{\max _{i \in M}\left\{\sum_{k=1}^{m} \delta\left(A_{i}, A_{k}\right)\right\}-\min _{i \in M}\left\{\sum_{k=1}^{m} \delta\left(A_{i}, A_{k}\right)\right\}},(i=1,2, \ldots, m)
$$


Step 4. Rank all the alternatives according to the overall values $\xi\left(A_{i}\right),(i=1,2, \ldots, m)$. Based on this result, we can get the conclusion that the most ideal alternative has largest overall value, and conversely, the worst alternative has the smallest value.

\subsection{Dual Pythagorean Hesitant Fuzzy Set}

In this part, some definitions of PFS, DHFS and DHPFS are introduced. The score function and accuracy function of DHPFN are also provided.

Definition 1 [22]). A Pythagorean fuzzy set (PFS) P with an object X is defined as follows:

$$
P=\left\{\left\langle x, u_{P}(x), v_{P}(x)\right\rangle \mid x \in X\right\}
$$

where $u_{P}(x) \in[0,1]$ is defined as the membership degree function, $v_{P}(x) \in[0,1]$ is defined as the non-membership degree function. For all $x \in X, u_{P}(x)$ and $v_{P}(x)$ meet the following requirements: $u_{P}(x)^{2}+v_{P}(x)^{2} \leq 1$. The hesitant degree of $x \in X$ is presented as:

$$
\pi_{P}(x)=\sqrt{1-u_{P}(x)^{2}-v_{P}(x)^{2}}, \forall x \in X
$$

For convenience, $\left(u_{P}(x), v_{P}(x)\right)$ is called a PFN, which can be denoted by $P=\left(u_{P}, v_{P}\right)$.

Definition 2 ([23]). Let $X$ be a fixed set, then a dual hesitant fuzzy set (DHFS) D with an object $X$ is defined as follows:

$$
D=\left\{\left\langle x, \Gamma_{D}(x), \Psi_{D}(x)\right\rangle \mid x \in X\right\}
$$

where $\Gamma_{D}(x) \in[0,1]$ is defined as a set of all the possible membership degrees, $\Psi_{D}(x) \in[0,1]$ is defined as a set of all the possible non-membership degrees.

Definition 3 ([5]). Let X be a fixed set, then a dual Pythagorean hesitant fuzzy set (DHPFS) A with an object $\mathrm{X}$ is defined as follows:

$$
A=\left\{\left\langle x, \Gamma_{A}(x), \Psi_{A}(x)\right\rangle \mid x \in X\right\}
$$

where $\Gamma_{A}(x) \in[0,1]$ is defined as a set of all the possible membership degrees, $\Psi_{A}(x) \in[0,1]$ is defined as a set of all the possible non-membership degrees. Furthermore, for all $u_{A}(x) \in \Gamma_{A}(x)$ and $v_{A}(x) \in \Psi_{A}(x)$ meet the following requirements: $u_{A}(x)^{2}+v_{A}(x)^{2} \leq 1$. The set of hesitant degree $x \in X$ is presented as:

$$
\Pi_{A}(x)=\underset{\substack{u_{A}(x) \in \Gamma_{A}(x) \\ v_{A}(x) \in \Psi_{A}(x)}}{U}\left\{\pi_{A}(x)=\sqrt{1-u_{A}(x)^{2}-v_{A}(x)^{2}} \geq 0\right\}, \forall_{x} \in X
$$

For convenience, $\left(\Gamma_{A}(x), \Psi_{A}(x)\right)$ is called a DHPFN, which can be denoted by $A=\left(\Gamma_{A}, \Psi_{A}\right)$.

Wei and $\mathrm{Lu}[5]$ have proposed some operational rules for DHPFN.

Definition 4 ([5]). Let $\beta_{1}=\left(\Gamma_{\beta 1}, \Psi_{\beta 1}\right), \beta_{2}=\left(\Gamma_{\beta 2}, \Psi_{\beta 2}\right)$ and $\beta=\left(\Gamma_{\beta}, \Psi_{\beta}\right)$ be three DHPFNs, then

$$
\begin{aligned}
& \text { (1) } \beta_{1} \oplus \beta_{2}=<\underset{u_{\beta 1(x)} \in \Gamma_{\beta 1(x)}}{U}\left\{\sqrt{u_{\beta 1}^{2}+u_{\beta 2}{ }^{2}-u_{\beta 1}^{2} u_{\beta 1}}\right\}, \underset{v_{\beta 1(x)} \in \Psi_{\beta 1(x)}}{\cup}\left\{v_{\beta 1} v_{\beta 2}\right\}>\text {; } \\
& u_{\beta 2(x)} \in \Gamma_{\beta 2(x)} \quad v_{\beta 2(x)} \in \Psi_{\beta 2(x)}
\end{aligned}
$$

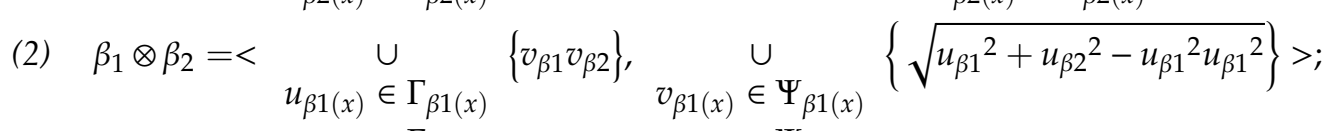

$$
\begin{aligned}
& u_{\beta 2(x)} \in \Gamma_{\beta 2(x)} \quad v_{\beta 2(x)} \in \Psi_{\beta 2(x)}
\end{aligned}
$$


(3) $\lambda \beta=<\underset{u_{\beta} \in \Gamma_{\beta}}{\cup}\left\{\sqrt{1-\left(1-u_{\beta}^{2}\right)^{\lambda}}\right\}, \underset{v_{\beta} \in \Psi_{\beta}}{\cup}\left\{v_{\beta}^{\lambda}\right\}>$;

(4) $\beta^{\lambda}=<\underset{u_{\beta} \in \Gamma_{\beta}}{\cup}\left\{u_{\beta}^{\lambda}\right\}, \underset{v_{\beta} \in \Psi_{\beta}}{\cup}\left\{\sqrt{1-\left(1-v_{\beta}^{2}\right)^{\lambda}}\right\}>$;

(5) $\beta^{c}=<\Psi_{\beta}, \Gamma_{\beta}>$;

Wei and $\mathrm{Lu}[5]$ gave a score function of DHPFNs to rank two different numbers.

Definition 5 ([5]). Let $\beta=\left(\Gamma_{\beta}, \Psi_{\beta}\right)$ be a DHPFN, then the score function of $\beta$ is defined as:

$$
S_{\beta}=\frac{1}{2}\left(1+\frac{1}{\left|\Gamma_{\beta}\right|} \sum_{u_{\beta} \in \Gamma_{\beta}} u_{\beta}^{2}-\frac{1}{\left|\Psi_{\beta}\right|} \sum_{v_{\beta} \in \Psi_{\beta}} v_{\beta}{ }^{2}\right)
$$

the accuracy function of $\beta$ is defined as:

$$
p_{\beta}=\frac{1}{\left|\Gamma_{\beta}\right|} \sum_{u_{\beta} \in \Gamma_{\beta}} u_{\beta}^{2}+\frac{1}{\left|\Psi_{\beta}\right|} \sum_{v_{\beta} \in \Psi_{\beta}} v_{\beta}^{2}
$$

$\left|\Gamma_{\beta}\right|$ and $\left|\Psi_{\beta}\right|$ represents the length of set $\Gamma_{\beta}$ and $\Psi_{\beta}$ respectively. The higher the score, the better the number.

\section{Dual Pythagorean Hesitant Fuzzy TODIM Approach}

In order to describe the dual Pythagorean hesitant fuzzy TODIM approach in detail, first of all, we put forward some fundamental concepts that are essential to this paper.

\subsection{Fundamental Knowledge}

According to Definition 5, Wei and Lu [5] gave a solution to compare two DHPFNs.

Definition 6 ([5]). Let $\beta_{1}=\left(\Gamma_{\beta 1}, \Psi_{\beta 1}\right)$ and $\beta_{2}=\left(\Gamma_{\beta 2}, \Psi_{\beta 2}\right)$ be two DHPFNs, $S_{\beta_{1}}$ and $S_{\beta_{2}}$ be the scores value of $\beta_{1}$ and $\beta_{2}$ respectively, $p_{\beta_{1}}$ and $p_{\beta_{2}}$ be the accuracy values of $\beta_{1}$ and $\beta_{2}$ respectively.

Then, if $S_{\beta_{1}}>S_{\beta_{2}}$, then $\beta_{1}>\beta_{2}$; if $S_{\beta_{1}}=S_{\beta_{2}}$, then

(1) if $p_{\beta_{1}}=p_{\beta_{2}}$, then $\beta_{1}=\beta_{2}$;

(2) if $p_{\beta_{1}}>p_{\beta_{2}}$, then $\beta_{1}>\beta_{2}$;

Definition 7 ([24]). Let $\beta_{1}=\left(\Gamma_{\beta 1}, \Psi_{\beta 1}\right)$ and $\beta_{2}=\left(\Gamma_{\beta 2}, \Psi_{\beta 2}\right)$ be two DHPFNs, then the Hamming distance between $\beta_{1}$ and $\beta_{2}$ is:

$$
d\left(\beta_{1}, \beta_{2}\right)=\frac{1}{2}\left(\frac{1}{l} \sum_{j=1}^{l}\left|\Gamma_{\beta 1}{ }^{\sigma(j)}-\Gamma_{\beta 2}{ }^{\sigma(j)}\right|+\frac{1}{m} \sum_{j=1}^{m}\left|\Psi_{\beta 1}{ }^{\sigma(j)}-\Psi_{\beta 2}{ }^{\sigma(j)}\right|\right)
$$

where l, mare the lengths of the set $\Gamma$ and $\Psi$, respectively. $\Gamma_{\beta 1}{ }^{\sigma(j)}, \Gamma_{\beta 2}{ }^{\sigma(j)}$ represents the jth largest element in set $\Gamma_{\beta 1}$ and $\Gamma_{\beta 2}$, respectively. $\Psi_{\beta 1}{ }^{\sigma(j)}, \Psi_{\beta 2}{ }^{\sigma(j)}$ represents the jth largest element in set $\Psi_{\beta 1}$ and $\Psi_{\beta 2}$, respectively.

In general, the number of elements in two DHPFS is different. Therefore, we use the extension principle to compare two sets, that is, adding elements to a set with fewer elements, so that the number of elements in the two sets is the same. There are two types of extension principles. The first is to add the largest element in the set, while the other is to add the smallest element in the set. In this article, we use the first principle. 
An example is shown to illustrate the Hamming distance between $\beta_{1}$ and $\beta_{2}$ : If $\beta_{1}=$ $\left(\{0.4,0.2\},\{0.7,0.3,0.1\}\right.$ and $\beta_{1}=(\{0.7,0.3,0.1\},\{0.4,0.1\}$ are two DHPFNs. Ar first, we extend set $\Gamma_{\beta 1}(x)=\{0.4,0.2\}$ to $\{0.4,0.4,0.2\}$ and set $\Psi_{\beta 2}(x)=\{0.4,0.1\}$ to $\{0.4,0.4,0.1\}$. Then the distance between $\beta_{1}$ and $\beta_{2}$ is: $d\left(\beta_{1}, \beta_{2}\right)=0.1500$.

\subsection{TODIM Method for Dual Hesitant Pythagorean Fuzzy MADM Problems}

Now, we give procedures to use TODIM approach to deal with MADM Problems with dual hesitant Pythagorean fuzzy set. In order to understand it easily, we describe the problems briefly as follows:

Let $A=\left\{A_{1}, A_{2}, \ldots, A_{m}\right\}$ be a discrete set of alternatives and $C=\left\{C_{1}, C_{2}, \ldots, C_{n}\right\}$ be the set of attributes; Let $=\left\{\omega_{1}, \omega_{2}, \ldots, \omega_{n}\right\}$ be the attributes set's weight vector, with $\omega_{j} \in[0,1]$ and $\sum_{j=1}^{n} \omega_{j}=1$. Suppose $R=\left(r_{i j}\right)_{m \times n}=\left(\Gamma_{i j}, \Psi_{i j}\right)_{m \times n}$ be a dual hesitant Pythagorean fuzzy decision matrix, where $r_{i j}$ is a criterion value according to a decision maker over the alternative. $A_{i}$ with respect to attribute $C_{j}$, where $\Gamma_{A(x)} \in[0,1]$ is defined as a set of all the possible membership degrees, $\Psi_{A(x)} \in[0,1]$ is defined as a set of all the possible non-membership degrees. Furthermore, for all $u_{A(x)} \in \Gamma_{A(x)}$ and $v_{A(x)} \in \Psi_{A(x)}$ meet the following requirements: $u_{A}(x)^{2}+v_{A}(x)^{2} \leq 1$.

Then, we extend the TODIM model to deal with the MADM problems with dual hesitant Pythagorean fuzzy set. At first, it is necessary to standardize the decision matrix, because there may be some benefit attribute and cost attribute in $C$, as they are two opposite DHPFNs:

$$
l_{i j}=\left\{\begin{array}{l}
r_{i j}, \text { forbene fitattributeC } \\
r_{i j}^{c} \text { for } \cos \text { tattribute } C_{j}
\end{array}\right.
$$

where $r_{i j}^{c}=\left(\Psi_{i j}, \Gamma_{i j}\right)$ is the complement of $r_{i j}^{c}$. After that, we can get the normalized dual hesitant Pythagorean fuzzy decision matrix $L=\left(l_{i j}\right)_{m \times n}$.

Next, we calculate the relative weight of the attribute $C_{j}$ to $C_{r}$ as

$$
\omega_{j r}=\omega_{j} / \omega_{r}(j, r=1,2, \ldots, n)
$$

where $\omega_{r}=\max \left\{\omega_{j} \mid j=1,2, \ldots, n\right\}, \omega_{j r} \in[0,1]$.

Then we can get the dominance degree of $A_{i}$ over attribute $C_{j}$ for each alternative $A_{k}$ :

$$
\phi j(A i, A k)= \begin{cases}\sqrt{d\left(l_{i j} \cdot l_{k j}\right) \omega_{j r} /\left(\sum_{j=1}^{n} \omega_{j r}\right)}, & l_{i j}>l_{k j} \\ 0, & l_{i j}=l_{k j} \\ -\frac{1}{\theta} \sqrt{d\left(l_{i j} \cdot l_{k j}\right)\left(\sum_{j=1}^{n} \omega_{j r}\right) / \omega_{j r}}, & l_{i j}<l_{k j}\end{cases}
$$

where the parameter $\theta$ represents the attenuation factor of the losses, $d\left(l_{i j} \cdot l_{k j}\right)$ describe the distance between the DHPFNs $l_{i j}$ and $l_{k j}$. In order to show the function $\phi_{j}\left(A_{i}, A_{k}\right)$ visually, we express it in a matrix way:

$$
\left.\phi_{j}\left(A_{i}, A_{k}\right)=\begin{array}{ccccc}
\mathrm{A}_{1} & \mathrm{~A}_{2} & \ldots & A_{m} \\
\mathrm{~A}_{1} & \mathrm{~A}_{2} \\
\vdots & \operatorname{Am} & \phi_{j}\left(A_{1}, A_{2}\right) & \ldots & \phi_{j}\left(A_{1}, A_{m}\right) \\
\phi_{j}\left(A_{2}, A_{1}\right) & 0 & \ldots & \phi_{j}\left(A_{2}, A_{m}\right) \\
\vdots & \vdots & \ldots & \vdots \\
\phi_{j}\left(A_{m}, A_{1}\right) & \phi_{j}\left(A_{m}, A_{2}\right) & \ldots & 0
\end{array}\right]
$$


based on which, we can calculate the overall dominance degree of the $A_{i}$ over each alternative $A_{k}$ by:

$$
\delta\left(A_{i}, A_{k}\right)=\sum_{j=1}^{n} \phi_{j}\left(A_{i}, A_{k}\right),(i, k=1,2, \ldots, m)
$$

and we also show the function $\delta\left(A_{i}, A_{k}\right)$ visually in a matrix:

$$
\left.\delta=\delta\left(A_{i}, A_{k}\right)_{m \times n}=\begin{array}{ccccc}
\mathrm{A}_{1} & \mathrm{~A}_{2} & \ldots & A_{m} \\
\mathrm{~A}_{1} & \mathrm{~A}_{2} \\
\vdots & 0 & \phi_{j}\left(A_{1}, A_{2}\right) & \ldots & \phi_{j}\left(A_{1}, A_{m}\right) \\
A_{m} & \vdots & \vdots & \ldots & \vdots \\
\phi_{j}\left(A_{2}, A_{1}\right) & 0 & \ldots & \phi_{j}\left(A_{2}, A_{m}\right) \\
\phi_{j}\left(A_{m}, A_{1}\right) & \phi_{j}\left(A_{m}, A_{2}\right) & \ldots & 0
\end{array}\right]
$$

Finally, the overall value of each alternative $A_{i}$ can be computed by the following formula:

$$
\xi\left(A_{i}\right)=\frac{\sum_{k=1}^{m} \delta\left(A_{i}, A_{k}\right)-\min _{i \in M}\left\{\sum_{k=1}^{m} \delta\left(A_{i}, A_{k}\right)\right\}}{\max _{i \in M}\left\{\sum_{k=1}^{m} \delta\left(A_{i}, A_{k}\right)\right\}-\min _{i \in M}\left\{\sum_{k=1}^{m} \delta\left(A_{i}, A_{k}\right)\right\}},(i=1,2, \ldots, m)
$$

In order to rank all alternatives, we construct a principle whereby that the greater the overall value of $\xi\left(A_{i}\right),(i=1,2, \ldots, m)$, the better the alternative $A_{i}$.

\section{Numerical Example}

\subsection{The Application of Dual Hesitant Pythagorean Fuzzy TODIM Approach}

In order to evaluate the borrower's default risk accurately, many models have been constructed. The first step in building the model is to select some reasonable credit evaluation indicators. Lin et al. [25] explored the factors that determine the default risk based on the demographic characteristics of borrowers. The empirical results show that the following ten factors played an important role in loan default: (1) gender, (2) age, (3) marital status, (4) educational level, (5) working years, (6) company size, (7) monthly payment, (8) loan amount, (9) debt to income ratio, and (10) delinquency history.

We denote these ten attributes as $C_{j}(j=1,2, \ldots, 10)$ respectively, and their weight vector is $\omega=(0.0550,0.0466,0.2005,0.1692,0.0766,0.0804,0.0821,0.1530,0.0655,0.0711)^{T}$, which is given by the decision maker. Suppose that there are four applicants to be ranked, which denoted as $A_{j}(j=1,2,3,4)$, and dual hesitant Pythagorean numbers $r_{i j}\left(\Gamma_{i j}, \Psi_{i j}\right)$ appear in the MADM process. $r_{i j}\left(\Gamma_{i j}, \Psi_{i j}\right)(\mathrm{i}=1,2,3,4 ; j=1,2, \ldots, 10)$ represents the value of alternative $A_{i}$ relative to attribute $C_{j}$. All these values are contained in the decision matrix $R=\left(r_{i j}\right)_{m \times n}=\left(\Gamma_{i j}, \Psi_{i j}\right)_{m \times n^{\prime}}$ as shown in Table 1 .

Table 1. The decision matrix $R$.

\begin{tabular}{cccccc}
\hline & $C_{1}$ & $C_{2}$ & $C_{3}$ & $C_{4}$ & $C_{5}$ \\
\hline$A_{1}$ & $(\{0.7,0.6\},\{0.7\})$ & $(\{0.4\},\{0.7,0.6\})$ & $(\{0.3\},\{0.8\})$ & $(\{0.4,0.3\},\{0.7,0.6\})$ & $(\{0.4\},\{0.7,0.6\})$ \\
$A_{2}$ & $(\{0.5,0.4\},\{0.6,0.5\})$ & $(\{0.5\},\{0.5,0.4\})$ & $(\{0.3,0.2\},\{0.8\})$ & $(\{0.5\},\{0.7\})$ & $(\{0.6,0.5\},\{0.7\})$ \\
$A_{3}$ & $(\{0.6,0.5\},\{0.5\})$ & $(\{0.5\},\{0.6\})$ & $(\{0.4\},\{0.7,0.6\})$ & $(\{0.4,0.3\},\{0.6\})$ & $(\{0.6,0.5\},\{0.8\})$ \\
$A_{4}$ & $(\{0.6,0.5\},\{0.5\})$ & $(\{0.5,0.4\},\{0.7\})$ & $(\{0.6\},\{0.8,0.7\})$ & $(\{0.7\},\{0.4,0.3\})$ & $(\{0.4,0.3\},\{0.7\})$ \\
\hline & $C_{6}$ & $C_{7}$ & $C_{8}$ & $C_{9}$ & $C_{10}$ \\
\hline$A_{1}$ & $(\{0.6,0.5\},\{0.6\})$ & $(\{0.5\},\{0.6,0.5\})$ & $(\{0.6\},\{0.7,0.6\})$ & $(\{0.5,0.4\},\{0.7\})$ & $(\{0.6\},\{0.7,0.6\})$ \\
$A_{2}$ & $(\{0.7\},\{0.6,0.5\})$ & $(\{0.5\},\{0.6,0.5\})$ & $(\{0.5,0.4\},\{0.8\})$ & $(\{0.5\},\{0.7\})$ & $(\{0.6,0.5\},\{0.7\})$ \\
$A_{3}$ & $(\{0.6,0.5\},\{0.5,0.4\})$ & $(\{0.7\},\{0.7\})$ & $(\{0.4\},\{0.6,0.5\})$ & $(\{0.7,0.6\},\{0.4\})$ & $(\{0.6\},\{0.8,0.7\})$ \\
$A_{4}$ & $(\{0.6\},\{0.6,0.5\})$ & $(\{0.6,0.5\},\{0.5\})$ & $(\{0.5\},\{0.7,0.6\})$ & $(\{0.6\},\{0.5,0.4\})$ & $(\{0.5,0.4\},\{0.6\})$ \\
\hline
\end{tabular}


Then, we can apply dual hesitant Pythagorean fuzzy TODIM approach to rank the personal default risk. Before that, we use extension principle which is claimed in this paper to extend the decision matrix, as shown in Table 2.

Table 2. The extended decision matrix $R$.

\begin{tabular}{|c|c|c|c|c|c|}
\hline & $C_{1}$ & $C_{2}$ & $C_{3}$ & $C_{4}$ & $C_{5}$ \\
\hline$A_{1}$ & $(\{0.7,0.6\},\{0.7,0.7\})$ & $(\{0.4,0.4\},\{0.7,0.6\})$ & $(\{0.3,0.3\},\{0.8,0.8\})$ & $(\{0.4,0.3\},\{0.7,0.6\})$ & $(\{0.4,0.4\},\{0.7,0.6\})$ \\
\hline$A_{2}$ & $(\{0.5,0.4\},\{0.6,0.5\})$ & $(\{0.5,0.5\},\{0.5,0.4\})$ & $(\{0.3,0.2\},\{0.8,0.8\})$ & $(\{0.5,0.5\},\{0.7,0.7\})$ & $(\{0.6,0.5\},\{0.7,0.7\})$ \\
\hline$A_{3}$ & $(\{0.6,0.5\},\{0.5,0.5\})$ & $(\{0.5,0.5\},\{0.6,0.6\})$ & $(\{0.4,0.4\},\{0.7,0.6\})$ & $(\{0.4,0.3\},\{0.6,0.6\})$ & $(\{0.6,0.5\},\{0.8,0.8\})$ \\
\hline \multirow[t]{2}{*}{$A_{4}$} & $(\{0.6,0.5\},\{0.5,0.5\})$ & $(\{0.5,0.4\},\{0.7,0.7\})$ & $(\{0.6,0.6\},\{0.8,0.7\})$ & $(\{0.7,0.7\},\{0.4,0.3\})$ & $(\{0.4,0.3\},\{0.7,0.7\})$ \\
\hline & $C_{6}$ & $C_{7}$ & $C_{8}$ & $C_{9}$ & $C_{10}$ \\
\hline$A_{1}$ & $(\{0.6,0.5\},\{0.6,0.6\})$ & $(\{0.5,0.5\},\{0.6,0.5\})$ & $(\{0.6,0.6\},\{0.7,0.6\})$ & $(\{0.5,0.4\},\{0.7,0.7\})$ & $(\{0.6,0.6\},\{0.7,0.6\})$ \\
\hline$A_{2}$ & $(\{0.7,0.7\},\{0.6,0.5\})$ & $(\{0.5,0.5\},\{0.6,0.5\})$ & $(\{0.5,0.4\},\{0.8,0.8\})$ & $(\{0.5,0.5\},\{0.7,0.7\})$ & $(\{0.6,0.5\},\{0.7,0.7\})$ \\
\hline$A_{3}$ & $(\{0.6,0.5\},\{0.5,0.4\})$ & $(\{0.7,0.7\},\{0.7,0.7\})$ & $(\{0.4,0.4\},\{0.6,0.5\})$ & $(\{0.7,0.6\},\{0.4,0.4\})$ & $(\{0.6,0.6\},\{0.8,0.7\})$ \\
\hline$A_{4}$ & $(\{0.6,0.6\},\{0.6,0.5\})$ & $(\{0.6,0.5\},\{0.5,0.5\})$ & $(\{0.5,0.5\},\{0.7,0.6\})$ & $(\{0.6,0.6\},\{0.5,0.4\})$ & $(\{0.5,0.4\},\{0.6,0.6\})$ \\
\hline
\end{tabular}

Firstly, $\omega_{3}=\max \left\{\omega_{j} \mid j=1,2, \ldots, 10\right\}=0.2005$, so we calculate the relative weights of the attribute are:

$$
\begin{gathered}
\omega_{13}=0.2743, \omega_{23}=0.2324, \omega_{33}=1.0000, \omega_{43}=0.8439, \omega_{53}=0.3820, \omega_{63}= \\
0.4010, \omega_{73}=0.4095, \omega_{83}=0.7631, \omega_{93}=0.3267, \omega_{103}=0.3546 .
\end{gathered}
$$

Then, we need to calculate the dominance degree of $A_{i}$ over each alternative $A_{k}$ with respect to the attribute $C_{j}(i, k=1,2,3,4 ; j=1,2, \ldots, 10)$. Let $\theta=2.5$ :

$$
\begin{aligned}
& \phi_{1}=\begin{array}{c}
\mathrm{A}_{1} \\
\mathrm{~A}_{1} \\
\mathrm{~A}_{2} \\
\mathrm{~A}_{3} \\
\mathrm{~A}_{4}
\end{array}\left[\begin{array}{cccc}
\mathrm{A}_{2} & \mathrm{~A}_{3} & \mathrm{~A}_{4} \\
-0.7928 & 0 & -0.5190 & -0.5190 \\
0.0908 & 0.0642 & 0 & 0 \\
0.0908 & 0.0642 & 0 & 0
\end{array}\right]
\end{aligned}
$$

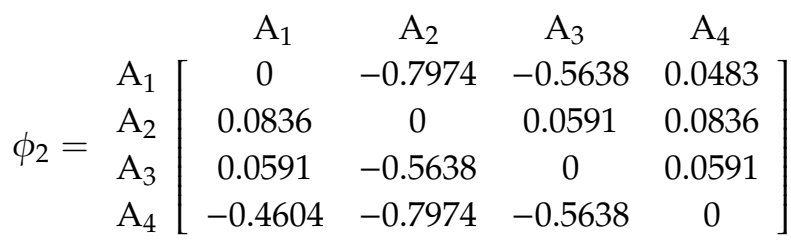

$$
\begin{aligned}
& \phi_{3}=\begin{array}{c}
\mathrm{A}_{1} \\
\mathrm{~A}_{1} \\
\mathrm{~A}_{2} \\
\mathrm{~A}_{3} \\
\mathrm{~A}_{4}
\end{array}\left[\begin{array}{cccc}
\mathrm{A}_{2} & \mathrm{~A}_{3} & \mathrm{~A}_{4} \\
-0.1569 & 0.0708 & -0.3509 & -0.4152 \\
0.1583 & 0.1734 & -0.3844 & -0.4439 \\
0.1873 & 0.2002 & 0.1734 & 0
\end{array}\right]
\end{aligned}
$$

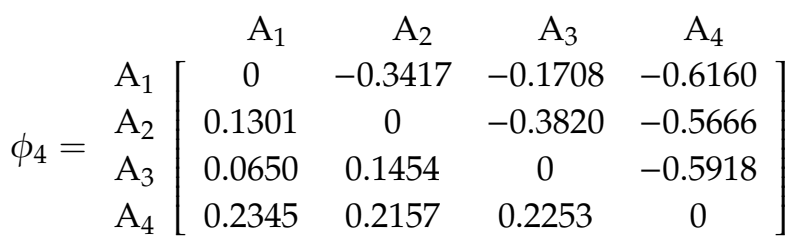




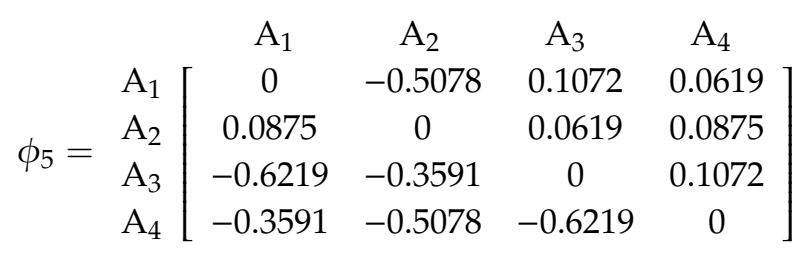$$
\phi_{6}=\begin{gathered}
\mathrm{A}_{1} \\
\mathrm{~A}_{1} \\
\mathrm{~A}_{2} \\
\mathrm{~A}_{3} \\
\mathrm{~A}_{4}
\end{gathered}\left[\begin{array}{cccc}
0 & \mathrm{~A}_{2} & \mathrm{~A}_{3} & \mathrm{~A}_{4} \\
0.0897 & 0 & 0.1002 & 0.0634 \\
0.0777 & -0.5542 & 0 & 0.0777 \\
0.0634 & -0.3505 & -0.4293 & 0
\end{array}\right]
$$$$
\phi_{7}=\begin{gathered}
\mathrm{A}_{1} \\
\mathrm{~A}_{2} \\
\mathrm{~A}_{3} \\
\mathrm{~A}_{4}
\end{gathered}\left[\begin{array}{cccc}
\mathrm{A}_{1} & \mathrm{~A}_{2} & \mathrm{~A}_{3} & \mathrm{~A}_{4} \\
0 & 0 & -0.6489 & -0.3468 \\
0 & 0 & -0.6489 & -0.3468 \\
0.1199 & 0.1199 & 0 & -0.6489 \\
0.0641 & 0.0641 & 0.1199 & 0
\end{array}\right]
$$

$$
\phi_{8}=\begin{array}{cccc}
\mathrm{A}_{1} & \mathrm{~A}_{2} & \mathrm{~A}_{3} & \mathrm{~A}_{4} \\
\mathrm{~A}_{1} \\
\mathrm{~A}_{2} \\
\mathrm{~A}_{3} \\
\mathrm{~A}_{4}
\end{array}\left[\begin{array}{cccc}
0.1515 & 0.1515 & 0.0875 \\
-0.4401 & 0 & -0.4401 & -0.3593 \\
-0.4401 & 0.1515 & 0 & 0.1237 \\
-0.2541 & 0.1237 & -0.3593 & 0
\end{array}\right]
$$

$$
\begin{aligned}
& \begin{array}{llll}
\mathrm{A}_{1} & \mathrm{~A}_{2} & \mathrm{~A}_{3} & \mathrm{~A}_{4}
\end{array} \\
& \phi_{9}=\begin{array}{c}
\mathrm{A}_{1} \\
\mathrm{~A}_{2} \\
\mathrm{~A}_{3} \\
\mathrm{~A}_{4}
\end{array}\left[\begin{array}{cccc}
0 & -0.2746 & -0.8683 & -0.7766 \\
0.0405 & 0 & -0.8237 & -0.7265 \\
0.1280 & 0.1214 & 0 & 0.0572 \\
0.1145 & 0.1071 & -0.3883 & 0
\end{array}\right]
\end{aligned}
$$

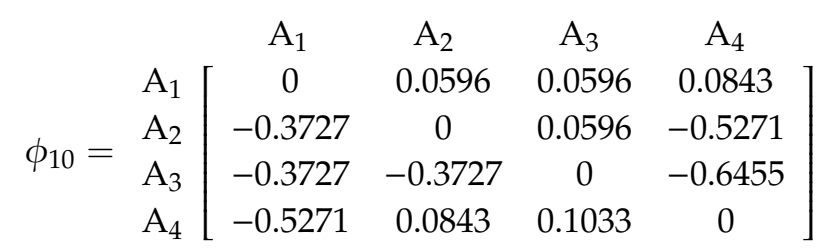

Secondly, we calculate the overall dominance degree of the $A_{i}$ over each alternative $A_{k}$ :

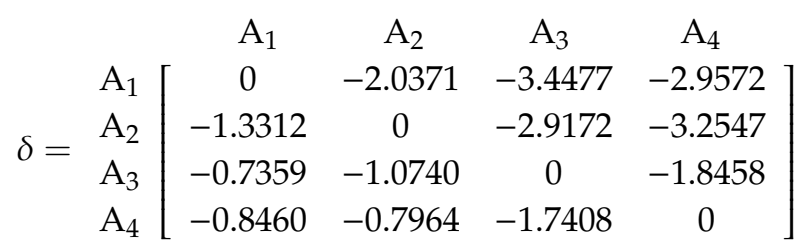

Finally, we can get the overall value of each alternative $A_{i}$ by the follows:

$$
\xi\left(A_{1}\right)=0 ; \xi\left(A_{2}\right)=0.1856 ; \xi\left(A_{3}\right)=0.9461 ; \xi\left(A_{4}\right)=1 ;
$$

Thus, the ranking of alternatives is $A_{4}>A_{3}>A_{2}>A_{1}$, and $A_{4}$ has best credit.

\subsection{Comparative Analysis}

In this section, some comparative analysis will be performed to compare our proposed method with the other two operators defined by Wei and $\mathrm{Lu}[5]$. 
4.2.1. Comparison with the Dual Hesitant Pythagorean Fuzzy Weighted Average Operator

Then, we contrast this method with a dual hesitant Pythagorean fuzzy weighted average (DHPFWA) operator proposed by Wei and Lu [5] as follows:

Definition 8 ([5]). Let $\alpha_{i}=\left(\Gamma_{\alpha_{i}}(x), \Psi_{\alpha_{i}}(x)\right) \in \operatorname{DHPFNs}(i=1,2, \ldots, n)$ and $\omega=\left\{\omega_{1}, \omega_{2}, \ldots, \omega_{n}\right\}^{T}$ be the attributes set's weight vector, with $\omega_{j} \in[0,1]$ and $\sum_{j=1}^{n} \omega j=1$, then

$$
\begin{aligned}
& \text { DHPFWA } A_{\omega}\left(\alpha_{1}, \alpha_{2}, \ldots, \alpha_{n}\right)=\omega_{1} \alpha_{1} \oplus \omega_{2} \alpha_{2} \oplus \ldots \oplus \omega_{n} \alpha_{n} \\
& =<u_{\alpha_{i} \in \Gamma_{\alpha_{i}}}\left\{\sqrt{1-\prod_{i=1}^{n}\left(1-u_{\alpha_{i}}^{2}\right)^{\omega_{i}}}\right\}, \cup_{v_{\alpha_{i}} \in \Psi_{\alpha_{i}}}\left\{\prod_{i=1}^{n} v_{\alpha_{i}}^{\omega_{i}}\right\}>
\end{aligned}
$$

We can get:

$$
\begin{aligned}
& A_{1}=(\{0.4982,0.4925,0.4884,0.4826,0.4878,0.4819,0.4777,0.4716, \\
&0.4886,0.4828,0.4785,0.4725,0.4779,0.4718,0.4674,0.4611\}, \\
&\{0.7012,0.6936,0.6849,0.6774,0.6908,0.6833,0.6747,0.6673, \\
& 0.6930,0.6854,0.6768,0.6694,0.6827,0.6752,0.6668,0.6595, \\
& 0.6832,0.6757,0.6672,0.6600,0.6730,0.6657,0.6573,0.6502, \\
& 0.6751,0.6678,0.6594,0.6522,0.6651,0.6579,0.6496,0.6425, \\
& 0.6962,0.6886,0.6800,0.6725,0.6858,0.6784,0.6699,0.6626, \\
& 0.6880,0.6805,0.6720,0.6647,0.6778,0.6704,0.6620,0.6548, \\
& 0.6783,0.6709,0.6625,0.6552,0.6682,0.6609,0.6526,0.6455, \\
&0.6703,0.6630,0.6547,0.6475,0.6603,0.6531,0.6450,0.6379\}) \\
& A_{2}=(\{0.5115,0.5033,0.4987,0.4901,0.5026,0.4941,0.4894,0.4806, \\
& 0.5037,0.4952,0.4906,0.4817,0.4945,0.4858,0.4810,0.4718, \\
& 0.5070,0.4986,0.4940,0.4853,0.4980,0.4893,0.4846,0.4755, \\
&0.4990,0.4904,0.4857,0.4767,0.4897,0.4809,0.4760,0.4667\}, \\
&\{0.6986,0.6882,0.6884,0.6782,0.6914,0.6811,0.6813,0.6712, \\
&0.6916,0.6814,0.6816,0.6714,0.6845,0.6743,0.6745,0.6645\}) \\
& A_{3}=(\{0.5303,0.5201,0.5216,0.5110,0.5220,0.5115,0.5130,0.5021, \\
& 0.5210,0.5104,0.5120,0.5011,0.5124,0.5015,0.5031,0.4918, \\
& 0.5244,0.5139,0.5154,0.5046,0.5159,0.5051,0.5066,0.4955, \\
&0.5149,0.5041,0.5056,0.4945,0.5061,0.4949,0.4965,0.4850\}, \\
&\{0.6213,0.6154,0.6042,0.5985,0.6102,0.6044,0.5934,0.5878, \\
& A_{4}=(\{0.5861,0.5816,0.5788,0.5741,0.5827,0.5781,0.5752,0.5705, \\
& 0.5832,0.5786,0.5757,0.5710,0.5797,0.5750,0.5721,0.5674, \\
& 0.5812,0.5766,0.5737,0.5690,0.5777,0.5730,0.5701,0.5653, \\
&0.5782,0.5735,0.5706,0.5658,0.5746,0.5699,0.5670,0.5621\}, \\
& 0.5688,0.5882,0.5829,0.5745,0.5882,0.5796,0.5744,0.5661, \\
& 0.5811,0.5726,0.5675,0.5593,0.5726,0.5643,0.5593,0.5512, \\
&0.5535,0.5454,0.5406,0.5327,0.5454,0.5375,0.5327,0.5250\})
\end{aligned}
$$

then, the score values of each alternative are as follows: $s_{A_{1}}=0.3914, s_{A_{2}}=0.3878, s_{A_{3}}=0.4521, s_{A_{4}}=$ 0.5080. We can get the ranking of alternatives according to the score value: $s_{A_{4}}>s_{A_{3}}>s_{A_{1}}>s_{A_{2}}$, and $A_{4}$ has best credit. 


\subsubsection{Comparison with the Dual Hesitant Pythagorean Fuzzy Weighted Geometric Operator}

Then, we contrast this method with dual hesitant Pythagorean fuzzy weighted geometric (DHPFWG) operator proposed by Wei and Lu [5] as follows:

Definition 9 ([5]). Let $\alpha_{i}=\left(\Gamma_{\alpha_{i}}(x), \Psi_{\alpha_{i}}(x)\right) \in \operatorname{DHPFNs}(i=1,2, \ldots, n)$ and $\omega=\left\{\omega_{1}, \omega_{2}, \ldots, \omega_{n}\right\}^{T}$ be the attributes set's weight vector, with $\omega_{j} \in[0,1]$ and $\sum_{j=1}^{n} \omega_{j}=1$, then

$$
\begin{gathered}
\operatorname{DHPFWG}_{\omega}\left(\alpha_{1}, \alpha_{2}, \ldots, \alpha_{n}\right)=\omega_{1} \alpha_{1} \otimes \omega_{2} \alpha_{2} \otimes \ldots \otimes \omega_{n} \alpha_{n} \\
=<u_{u_{\alpha_{i}} \in \Gamma_{\alpha_{i}}}\left\{\prod_{i=1}^{n} u_{\alpha_{i}}^{\omega_{i}}\right\}, \bigcup_{v_{\alpha_{i}} \in \Psi_{\alpha_{i}}}\left\{\sqrt{1-\prod_{i=1}^{n}\left(1-v_{\alpha_{i}}^{2}\right)^{\omega_{i}}}\right\}>
\end{gathered}
$$

We can get:

$$
\begin{aligned}
A_{1}= & (\{0.4553,0.4487,0.4487,0.4422,0.4337,0.4274,0.4274,0.4212, \\
& 0.4515,0.4449,0.4449,0.4384,0.4300,0.4238,0.4238,0.4176\}, \\
& \{0.7117,0.7060,0.6993,0.6934,0.7071,0.7014,0.6945,0.6884, \\
& 0.7056,0.6998,0.6929,0.6868,0.7009,0.6950,0.6880,0.6817, \\
& 0.6980,0.6920,0.6849,0.6785,0.6932,0.6870,0.6798,0.6733, \\
& 0.6915,0.6854,0.6781,0.6715,0.6866,0.6803,0.6728,0.6662, \\
& 0.7080,0.7023,0.6954,0.6894,0.7034,0.6975,0.6906,0.6844, \\
& 0.7018,0.6959,0.6889,0.6827,0.6970,0.6910,0.6839,0.6775, \\
& 0.6941,0.6880,0.6808,0.6743,0.6892,0.6829,0.6756,0.6690, \\
& 0.6875,0.6812,0.6738,0.6672,0.6825,0.6761,0.6685,0.6617\}) \\
A_{2}= & (\{0.4764,0.4702,0.4604,0.4544,0.4698,0.4637,0.4540,0.4481, \\
& 0.4392,0.4335,0.4244,0.4190,0.4331,0.4275,0.4185,0.4131, \\
& 0.4705,0.4645,0.4548,0.4489,0.4640,0.4580,0.4484,0.4427, \\
& 0.4338,0.4282,0.4192,0.4138,0.4278,0.4223,0.4134,0.4081\}, \\
& \{0.7195,0.7151,0.7152,0.7107,0.7177,0.7133,0.7134,0.7088, \\
& 0.7165,0.7121,0.7122,0.7076,0.7147,0.7102,0.7103,0.7058\}) \\
A_{3}= & (\{0.4924,0.4874,0.4852,0.4803,0.4856,0.4807,0.4785,0.4737, \\
& 0.4690,0.4643,0.4622,0.4575,0.4625,0.4578,0.4558,0.4512, \\
& 0.4875,0.4826,0.4804,0.4755,0.4807,0.4759,0.4737,0.4690, \\
& 0.4643,0.4596,0.4576,0.4530,0.4579,0.4533,0.4512,0.4467\}, \\
& \{0.6531,0.6420,0.6423,0.6307,0.6491,0.6378,0.6381,0.6263, \\
& 0.6324,0.6203,0.6206,0.6080,0.6280,0.6158,0.6160,0.6033\}) \\
A_{4}= & (\{0.5683,0.5593,0.5598,0.5510,0.5559,0.5471,0.5476,0.5390, \\
& 0.5624,0.5535,0.5540,0.5453,0.5501,0.5415,0.5420,0.5334, \\
& 0.5626,0.5537,0.5542,0.5455,0.5503,0.5417,0.5422,0.5336, \\
& 0.5568,0.5480,0.5485,0.5399,0.5446,0.5361,0.5366,0.5281\}, \\
& \{0.6487,0.6454,0.6328,0.6292,0.6430,0.6396,0.6267,0.6230, \\
& 0.6426,0.6392,0.6263,0.6226,0.6367,0.6332,0.6200,0.6163, \\
& 0.6156,0.6118,0.5975,0.5935,0.6091,0.6052,0.5906,0.5864, \\
& 0.6087,0.6048,0.5901,0.5860,0.6020,0.5981,0.5830,0.5788\})
\end{aligned}
$$

then, the score values of each alternative are as follows: $s_{A_{1}}=0.3587, s_{A_{2}}=0.3436, s_{A_{3}}=0.4122, s_{A_{3}}=$ 0.4607. We can get the rank of all alternatives according to the score values: $s_{A_{4}}>s_{A_{3}}>s_{A_{1}}>s_{A_{2}}$, and $A_{4}$ has best credit.

The results of comparative analyses by using different methods are as follows:

As you can see from Table 3 , the three methods have the same best choice $A_{4}$ and their results are slightly different. Obviously, the proposed method considers the attitude of decision makers towards risk, that is, people are more sensitive to loss than gain, which makes the results of decisions consistent with the expectations of decision makers. Each of these methods has its own advantages: (1) DHPFWA 
operator is affected by groups, (2) DHPFWG operator is affected by individuals, and (3) the dual hesitant Pythagoras fuzzy TODIM method reduces uncertainty while taking into account the psychological characteristics of lenders to avoid risk. Today's credit environment is full of risks, and the psychological behaviors of decision makers are important factors that cannot be ignored. So, the dual Pythagorean hesitant fuzzy TODIM method is applicable for evaluating personal default risk.

Table 3. Rank of alternatives by using different methods.

\begin{tabular}{ll}
\hline & Ordering \\
\hline Dual Hesitant Pythagoras Fuzzy TODIM & $A_{4}>A_{3}>A_{2}>A_{1}$ \\
DHPFWA & $A_{4}>A_{3}>A_{1}>A_{2}$ \\
DHPFWG & $A_{4}>A_{3}>A_{1}>A_{2}$ \\
\hline
\end{tabular}

\section{Concluding Remarks and Suggestions}

In the decision-making environment full of risks, the TODIM method enables decision-makers' psychological behaviors to be described. But it doesn't work when it's used directly to solve the MADM problems with fuzzy information. Through existing research, we can find that the membership and non-membership of the dual hesitant Pythagoras fuzzy set are respectively represented by a set containing all possible values, this fuzzy set is a good tool for people to express hesitancy in daily life. Therefore, we have proposed a method named dual hesitant Pythagoras fuzzy TODIM to solve MADM problem with dual hesitant Pythagoras fuzzy information. One of the most important advantages of the proposed approach is that it can reduce uncertainty while taking the psychological characteristics of lenders into account to avoid risk. At the same time, this method can be further extended to other similar MADM problems with interdependent attribute under dual hesitant Pythagoras fuzzy environments, such as performance evaluation, risk investment and so on. At last, the dual hesitant Pythagoras fuzzy has made a great contribution to the expansion of fuzzy set and also plays a significant role in practical decision process.

In this paper, the dual hesitant Pythagoras fuzzy TODIM method is applied to the case of personal default risk evaluation in the P2P lending platforms, and some comparative analyses are performed to compare the dual hesitant Pythagorean fuzzy TODIM method with the other two integrated operators DHPFWA and DHPFWG. The advantage of the dual hesitant Pythagoras fuzzy TODIM method over these two operators is that it takes the decision maker's reference dependence and the psychological behavior characteristics of loss aversion into account. We have demonstrated that the proposed approach is applicable for evaluating personal default risk through the comparisons. More broadly, it can also be applied to solve more similar MADM problems. In the future, we shall continue studying the MADM problems with the application and extension of the developed operators to other domains [26-33].

Finally, in view of the macroeconomic downturn and strong financial supervision, we would like to put forward the following suggestions to prevent default risk of P2P online platforms: (1) Improve the information disclosure system to reduce information asymmetry. On the one hand, online loan platforms should actively participate in relevant regulatory associations and fully disclose the information of the borrowers; on the other hand, it is necessary and even desirable to examine the authenticity and legitimacy of the information and issue a reliable risk assessment report. (2) Establish a third-party depository system. On the one hand, the funds of the loan project should be managed by a special third-party financial institution like a bank, and the online loan platforms are only used as a medium for information interaction. On the other hand, it avoids short-term goals and extracts a certain percentage of risk reserves to protect the investment. This can improve the anti-risk ability of online loan platforms, and also enhance investors' confidence in the platform.

Author Contributions: Data curation, L.Y.; writing—review and editing, L.Y.; investigation, X.J.; writing—original draft preparation, X.J.; software, J.F. All authors have read and agreed to the published version of the manuscript. 
Funding: This work was supported by the National Social Science Foundation the People's Republic of China (No. 19BJL025) and the Humanities and Social Sciences Foundation of the Ministry of Education of the People's Republic of China (No.17YJA790088)

Conflicts of Interest: The authors declare no conflicts of interest.

\section{References}

1. Malekipirbazari, M.; Aksakalli, V. Risk assessment in social lending via random forests. Expert Syst. Appl. 2015, 42, 4621-4631. [CrossRef]

2. Serrano-Cinca, C.; Gutiérrez-Nieto, B. The use of profit scoring as an alternative to credit scoring systems in peer-to-peer (P2P) lending. Decis. Support Syst. 2016, 89, 113-122. [CrossRef]

3. Oreski, S.; Oreski, G. Genetic algorithm-based heuristic for feature selection in credit risk assessment. Expert Syst. Appl. 2014, 41, 2052-2064. [CrossRef]

4. Guo, Y.H.; Zhou, W.J.; Luo, C.Y.; Liu, C.R.; Hui, X. Instance-based credit risk assessment for investment decisions in P2P lending. Eur. J. Oper. Res. 2016, 249, 417-426. [CrossRef]

5. Wei, G.W.; Lu, M. Dual hesitant pythagorean fuzzy Hamacher aggregation operators in multiple attribute decision making. Arch. Control Sci. 2017, 27, 365-395. [CrossRef]

6. Lu, J.P.; Tang, X.Y.; Wei, G.W.; Wei, C.; Wei, Y. Bidirectional project method for dual hesitant Pythagorean fuzzy multiple attribute decision-making and their application to performance assessment of new rural construction. Int. J. Intell. Syst. 2019, 34, 1920-1934. [CrossRef]

7. Simon, H.A. Administrative Behavior. Am. J. Nurs. 1950, 50, 46-47. [CrossRef]

8. Tversky, K.A. Prospect Theory: An Analysis of Decision under Risk. Econometrica 1979, 47, $263-292$.

9. Fan, Z.P.; Zhang, X.; Chen, F.D.; Liu, Y. Multiple attribute decision making considering aspiration-levels: A method based on prospect theory. Comput. Ind. Eng. 2013, 65, 341-350. [CrossRef]

10. Gomes, L.F.A.M.; Lima, M.M.P.P. TODIM: Basics and application to multicriteria ranking of projects with environmental impacts. Found. Comput. Decis. Sci. 1992, 16, 113-127.

11. Gomes, L.F.A.M.; Rangel, L.A.D.; Maranh?o, F.J.C. Multicriteria analysis of natural gas destination in Brazil: An application of the TODIM method. Math. Comput. Model. 2009, 50, 92-100. [CrossRef]

12. Tseng, M.L.; Lin, Y.H.; Tan, K.; Chen, R.H.; Chen, Y.H. Using TODIM to evaluate green supply chain practices under uncertainty. Appl. Math. Model. 2014, 38, 2983-2995. [CrossRef]

13. Fan, Z.P.; Zhang, X.; Chen, F.D.; Liu, Y. Extended TODIM method for hybrid multiple attribute decision making problems. Knowl.-Based Syst. 2013, 42, 40-48. [CrossRef]

14. Lourenzutti, R.; Krohling, R.A. A study of TODIM in a intuitionistic fuzzy and random environment. Expert Syst. Appl. 2013, 40, 6459-6468. [CrossRef]

15. Ren, P.J.; Xu, Z.S.; Gou, X.J. Pythagorean fuzzy TODIM approach to multi-criteria decision making. Appl. Soft. Comput. 2016, 42, 246-259. [CrossRef]

16. Liu, N.Y. Hesitant Fuzzy TODIM Multiple Attribute Decision-making Method Based on Attribute Association. J. Chongqing Technol. Bus. Univ. 2018, 35, 32-39.

17. Wei, G.W. TODIM Method for Picture Fuzzy Multiple Attribute Decision Making. Informatica 2018, 29, 555-566. [CrossRef]

18. Huang, Y.H.; Wei, G.W. TODIM method for Pythagorean 2-tuple linguistic multiple attribute decision making. J. Intell. Fuzzy Syst. 2018, 35, 901-915. [CrossRef]

19. Ji, P.; Zhang, H.Y.; Wang, J.Q. A projection-based TODIM method under multi-valued neutrosophic environments and its application in personnel selection. Neural Comput. Appl. 2016, 29, 221-234. [CrossRef]

20. Tian, X.L.; Xu, Z.S.; Gu, J. An Extended TODIM Based on Cumulative Prospect Theory and Its Application in Venture Capital. Informatica 2019, 30, 413-429. [CrossRef]

21. Yin, J.L.; Guo, J.; Ji, T.M. An Extended TODIM Method for Project Manager's Competency Evaluation. J. Civ. Eng. Manag. 2019, 25, 673-686. [CrossRef]

22. Yager, R.R. Pythagorean Membership Grades in Multicriteria Decision Making. IEEE Trans. Fuzzy Syst. 2014, 22, 958-965. [CrossRef]

23. Zhu, B.; Xu, Z.S.; Xia, M.M. Dual Hesitant Fuzzy Sets. J. Appl. Math. 2012, 2012, 2607-2645. [CrossRef]

24. Ren, Z.L.; Xu, Z.S.; Wang, H. Dual hesitant fuzzy VIKOR method for multi-criteria group decision making based on fuzzy measure and new comparison method. Inf. Sci. 2017, 388-389, 1-16. [CrossRef] 
25. Lin, X.C.; Li, X.L.; Zheng, Z. Evaluating borrower's default risk in peer-to-peer lending: Evidence from a lending platform in China. Appl. Econ. Lett. 2016, 1-8. [CrossRef]

26. Lu, J.P.; Wei, C.; Wu, J.; Wei, G.W. TOPSIS method for probabilistic linguistic magdm with entropy weight and its application to supplier selection of new agricultural machinery products. Entropy 2019, 21, 953. [CrossRef]

27. Zhang, S.Q.; Wei, G.W.; Gao, H.; Wei, C.; Wei, Y. EDAS method for multiple criteria group decision making with picture fuzzy information and its application to green suppliers selections. Technol. Econ. Dev. Econ. 2019, 25, 1123-1138. [CrossRef]

28. Gao, H.; Wu, J.; Wei, C.; Wei, G.W. MADM method with Interval-valued Bipolar Uncertain Linguistic Information for Evaluating the Computer Network Security. IEEE Access 2019, 7, 151506-151524. [CrossRef]

29. Gao, H.; Lu, M.; Wei, Y. Dual hesitant bipolar fuzzy hamacher aggregation operators and their applications to multiple attribute decision making. J. Intell. Fuzzy Syst. 2019, 37, 5755-5766. [CrossRef]

30. Wu, L.P.; Gao, H.; Wei, C. VIKOR method for financing risk assessment of rural tourism projects under interval-valued intuitionistic fuzzy environment. J. Intell. Fuzzy Syst. 2019, 37, 2001-2008. [CrossRef]

31. Li, Z.X.; Lu, M. Some novel similarity and distance and measures of Pythagorean fuzzy sets and their applications. J. Intell. Fuzzy Syst. 2019, 37, 1781-1799. [CrossRef]

32. Deng, X.M.; Gao, H. TODIM method for multiple attribute decision making with 2-tuple linguistic Pythagorean fuzzy information. J. Intell. Fuzzy Syst. 2019, 37, 1769-1780. [CrossRef]

33. Wang, R. Research on the Application of the Financial Investment Risk Appraisal Models with Some Interval Number Muirhead Mean Operators. J.Intell.Fuzzy Syst. 2019, 37, 1741-1752. [CrossRef]

(C) 2019 by the authors. Licensee MDPI, Basel, Switzerland. This article is an open access article distributed under the terms and conditions of the Creative Commons Attribution (CC BY) license (http://creativecommons.org/licenses/by/4.0/). 